\title{
Respiratory failure as initial symptom of acid maltase deficiency
}

\author{
RWM KEUNEN, ${ }^{*}$ PCLA LAMBREGTS, ${ }^{*}$ AAW OP DE COUL, ${ }^{*}$ EMG JOOSTEN $\dagger$ \\ From St Elisabeth Hospital, Tilburg* and St Radboud Hospital, University of Nijmegen, $\dagger$ The Netherlands.
}

SUMMARY Nine patients with adult onset acid maltase deficiency were seen at the Nijmegen University Hospital and the St Elisabeth Hospital, Tilburg, during the period 1970-1982. Five of these patients developed respiratory failure, and in four this was the initial symptom. The occurrence of respiratory failure as an early symptom of this muscular disease is discussed.

The syndrome of rapidly progressive unexplained dyspnoea is dramatic. If it entails respiratory failure, artificial ventilation is resorted to. The cause is usually a cardio-pulmonary disease but in some cases a neuromuscular disease may be involved. In neuromuscular diseases respiratory failure is as a rule a terminal symptom, and in these cases the history and the results of examination rapidly lead to a diagnosis. In rare cases, however, respiratory failure can be a presenting symptom of a neuromuscular disease. Newsom Davis, ${ }^{1}$ Rosenow, ${ }^{2}$ Bellamy, ${ }^{3}$ and Lightman ${ }^{4}$ described patients with respiratory failure as the initial symptom of adult onset acid maltase deficiency.

Nine patients with adult onset acid maltase deficiency were seen at the Nijmegen University Hospital and the St Elisabeth Hospital, Tilburg, during the period 1970-1982 (table 1). Respiratory failure was predominant in five of these patients, and in four it was the initial symptom. Early diagnosis of this disease is important with a view to therapy and genetic counselling.

\section{Case reports}

Patient 1 was hospitalised in 1982 with progressive dyspnoea of a few days' standing. During the past few months his family doctor had given him antibiotics in an unsuccessful attempt to control his bronchitis.

There was a history of hilar pulmonary tuberculosis at the age of 2 years. In 1976 the patient had been examined elsewhere by a neurologist in view of low back symptoms. The examination revealed no abnormalities other than areflexia of the extremities. An EMG recorded at that time

Address for reprint requests: Dr RWM Keunen, Neurological Dept, St Elisabeth Hospital, Hilvarenbeekseweg 60, 5000 LC Tilburg, The Netherlands

Received 8 November 1983. Accepted 2 December 1983 revealed no evidence of a myopathy or neuropathy. The parents are non-consanguineous and there was no family history of neuromuscular disease. The physical findings and the chest radiograph at admission indicated cardiac decompensation as a possible cause of the dyspnoea, and the patient was therefore artificially ventilated and treated with diuretics. The decompensation thereupon disappeared, but nevertheless weaning from ventilation was impossible without adverse effects.

This prompted a neurological consultation. The ventilation precluded the taking of a reliable history. Consciousness was clear and orientation intact. There was no cranial nerve disorder. The extremities showed mild proximal paresis with areflexia. Plantar reflexes were normal. There was mild diffuse muscular atrophy without symptoms of myotonia.

In view of the respiratory failure in combination with mild proximal muscle weakness and the increased creatine kinase (CK) level (table 1), the possibility of adult onset acid maltase deficiency was considered. An EMG recorded on this assumption (see table 1) indicated a generalised myopathy. Biochemical studies revealed acid maltase deficiency in the leucocytes (table 1) and also disclosed a second enzyme defect: a decreased myoadenylate deaminase level. A muscle biopsy (table 1) confirmed the diagnosis. Questioning revealed that the patient had had only moderate muscular strength since childhood, although he had never been regarded as sickly. A family study of his parents, three brothers and one sister disclosed carriers in the parents and two brothers and identified the sister as a patient who showed no symptoms other than very mild proximal muscular paresis. The patient was weaned from ventilation after 16 days and discharged from hospital after 2 months. After 7 months severe dyspnoea necessitated resumption of ventilation. He has since shown considerable improvement but still requires ventilation at night.

Patient 2 was a 45-year-old man who was hospitalised in 1978 with acute respiratory failure. During the week preceding admission he had complained of progressive dyspnoea, which the family doctor had unsuccessfully tried to treat with antibiotics. There was a history of Prominal (methylphenobarbital) intoxication in 1976. At that time it 
Table 1 Survey of patients

\begin{tabular}{|c|c|c|c|c|c|c|c|c|}
\hline \multicolumn{2}{|c|}{$\begin{array}{l}\text { Patient Sex } \\
\text { number }\end{array}$} & \multirow{2}{*}{$\begin{array}{l}\begin{array}{c}\text { Age } \\
(y r)\end{array} \\
34\end{array}$} & \multirow{2}{*}{$\begin{array}{l}\begin{array}{l}\text { Initial } \\
\text { symptom }\end{array} \\
\text { Dyspnoea }\end{array}$} & \multirow{2}{*}{$\begin{array}{c}C K^{*} \\
1000\end{array}$} & \multirow{2}{*}{$\begin{array}{l}\text { EMG } \\
\text { Prox musc slimmed motor } \\
\text { units with marked polyphasia. } \\
\text { Paravertebral pseudomyotonic } \\
\text { volleys }\end{array}$} & \multirow{2}{*}{$\begin{array}{l}\text { Acid maltase level } \dagger \\
\text { Decreased } \\
\text { L } 36(78-284) \\
\text { M } 0 \cdot 37(20-65)\end{array}$} & \multirow{2}{*}{$\begin{array}{l}\text { Muscle biopsy } \\
\begin{array}{l}\text { Vacuolar lysosomal } \\
\text { glycogen storage }\end{array}\end{array}$} & \multirow{2}{*}{ Remarks } \\
\hline 1 & $\mathbf{M}$ & & & & & & & \\
\hline 2 & $\mathbf{M}$ & 45 & Dyspnoea & $\mathbf{N}$ & Prox \& dist musc. normal & $\begin{array}{l}\text { Normal } \\
\text { L } 41(20-65) \\
\text { M } 2 \cdot 9(20-65)\end{array}$ & idem & Brother of pat. $3 \div$ \\
\hline 3 & $\mathbf{M}$ & 33 & Dyspnoea & $\mathbf{N}$ & Not recorded & $\begin{array}{l}\text { Decreased } \\
\text { L } 24(78-284)\end{array}$ & idem & $\begin{array}{l}\text { Oligophrenic. } \\
\text { Brother of pat. } 2\end{array}$ \\
\hline 4 & $\mathbf{M}$ & 20 & Dyspnoea & 424 & $\begin{array}{l}\text { Prox \& dist musc. non- } \\
\text { specific myopathic } \\
\text { changes }\end{array}$ & Not determined & idem & $\begin{array}{l}\text { Progressive course } \\
\text { with resp. failure } \overline{\overline{\mathrm{D}}} \\
\text { Brother of pat. } 8\end{array}$ \\
\hline 5 & $\mathbf{M}$ & 40 & $\begin{array}{l}\text { Loss of } \\
\text { strength } \\
\text { extrem. }\end{array}$ & - & Not recorded & Not determined & Vacuolar myopathy & Brother of pat. 6 \\
\hline 6 & $\mathbf{F}$ & 45 & Pain $\mathbf{R}$ hip & 257 & $\begin{array}{l}\text { Prox musc. normal Dist. } \\
\text { musc. sporadic myotonic } \\
\text { volleys }\end{array}$ & $\begin{array}{l}\text { Decreased } \\
\text { L } 15(20-65)\end{array}$ & $\begin{array}{l}\text { Vacuolar lysosomal } \\
\text { glycogen storage }\end{array}$ & Sister of pat. $5 \&$ \\
\hline 7 & $\mathbf{F}$ & 30 & $\begin{array}{l}\text { Loss of } \\
\text { strength } \\
\text { extrem. }\end{array}$ & 115 & $\begin{array}{l}\text { Prox musc. slimmed motor } \\
\text { units with marked } \\
\text { polyphasia }\end{array}$ & $\begin{array}{l}\text { Decreased } \\
\text { L } 25(20-55) \\
\text { M } 3.4(20-65)\end{array}$ & idem & Sister of pat. $5 \&$ \\
\hline 8 & $\mathbf{M}$ & 6 & $\begin{array}{l}\text { Asymptomatic } \\
\text { gener. musc } \\
\text { atrophy }\end{array}$ & 3468 & $\begin{array}{l}\text { Prox musc. slimmed motor } \\
\text { units with marked polyphasia } \\
\text { and pseudomyotonic volleys }\end{array}$ & $\begin{array}{l}\text { Decreased } \\
\text { M } 0.6(10-55)\end{array}$ & idem & Brother of pat. $4 \underset{7}{\frac{7}{7}}$ \\
\hline 9 & $\mathbf{F}$ & 7 & Chron cough & 380 & idem & $\begin{array}{l}\text { Decreased } \\
\text { L } 12(20-65)\end{array}$ & idem & $\begin{array}{l}\text { MCT‡ diet without } \\
\text { success }\end{array}$ \\
\hline
\end{tabular}

${ }^{*} \mathrm{~N}=$ less than $100 \mathrm{U} / 1$

$\dagger$ Units leucocytes $(\mathrm{L}): \mathrm{nmol} / \mathrm{h} / \mathrm{mg}$ protein musculature $(\mathbf{M}): \mathrm{nmol} / \mathrm{min} / \mathrm{g}$ muscle

(normal range given in brackets)

$¥$ Medium chain triglycerides

had already been noticed that the patient used his accessory respiratory muscles. In view of his habitus the patient had been erroneously identified as suffering from Marfan's disease. Examination revealed a thin man with thoracic kyphosis. Blood pressure was $130 / 80 \mathrm{~mm} \mathrm{Hg}$; tachycardia, vesicular respiratory murmur over the lungs and loud percussion sounds, and systolic souffle over the heart were found. No biochemical abnormalities other than respiratory acidosis were found and CK level was normal. The chest radiograph showed slight infiltrates. The ECG was normal. Sputum cultures were repeatedly negative. Pneumonia with respiratory failure was diagnosed and ventilation started, from which the patient could not be weaned despite adequate therapy. Questioning revealed that the patient had slept in a sitting position during the past few months and had had difficulties walking stairs. Neurological examination showed restricted abduction and adduction of the left eye. The facial nerves were intact. There was bilateral atrophy of the musculature of the shoulders, trunk and thighs, which was less pronounced distally. The distal parts of the extremities were stronger than the proximal parts. No fasciculations were seen. Sensory functions were intact and the arms showed normal reflexes, whereas the legs showed areflexia. There were no biochemical abnormalities and the EMG was normal (table 1). The acid maltase content of the leucocytes was not diminished. The muscle biopsy, however, was conclusive of acid maltase deficiency biochemically. The patient was weaned from ventilation after 4 weeks, but one week later ventilation had to be resumed. This sequence of ventilation and weaning was repeated thrice until the patient was finally weaned with marginal ventilation. He died from aspiration pneumonia in January 1979.

Patient 3 was a 33-year-old man admitted after two days of progressive dyspnoea. He had recently suffered from persistent bronchitis which had poorly responded to courses of antibiotics. He was known to be mentally deficient. Examination showed a thin, cyanotic man with a lowered level of consciousness. Blood pressure was $180 / 70 \mathrm{~mm} \mathrm{Hg}$ and tachycardia was present. No neurological abnormality other than overall muscular atrophy was found. Biochemical findings indicated respiratory acidosis without other abnormalities. The chest radiograph showed atelectasis of the right lower lobe. The ECG was normal. The patient was intubated and ventilated. Weaning from ventilation was difficult despite the good cardiopulmonary condition (table 2). The family history showed that his brother (patient 2) had died from respiratory failure as a result of acid maltase deficiency. The prognosis was unfavourable owing to progressive respiratory failure with epileptic seizures. The patient died showing the symptoms of intractable status epilepticus. Necropsy confirmed the diagnosis of acid maltase deficiency.

Patient 4 was a 20-year-old man admitted on 12 January 1981 with dysphagia and progressive dyspnoea. He had been examined by a paediatrician in 1973 because of his muscular weakness. His brother (patient 8) likewise showed diminished muscular strength due to acid maltase deficiency. The patient was using anti-epileptics to control posttraumatic epilepsy. Examination showed an extremely 
Table 2 Patients with respiratory failure

\begin{tabular}{|c|c|c|c|c|}
\hline $\begin{array}{l}\text { Patient } \\
\text { Artificially ventilated } \\
\text { First period of ventilation }\end{array}$ & $\begin{array}{c}1 \\
\text { yes }\end{array}$ & $\begin{array}{c}2 \\
\text { yes }\end{array}$ & $\begin{array}{l}3 \\
\text { yes }\end{array}$ & $\begin{array}{l}4 \\
\text { no }\end{array}$ \\
\hline duration preceding dyspnoea (days) & $\begin{array}{r}4 \\
16\end{array}$ & 7 & 2 & - \\
\hline $\begin{array}{l}\text { Subsequent periods of ventilation } \\
\text { number } \\
\text { final condition }\end{array}$ & $\begin{array}{l}1 \\
\text { ventil } \\
\text { at night }\end{array}$ & $t^{2}$ & $\begin{array}{l}1 \\
\dagger\end{array}$ & $\bar{t}$ \\
\hline
\end{tabular}

thin, tall young man with myopathic facies and generalised muscular atrophy but intact locomotor function. The humeroscapular and pelvic muscles showed unmistakable insufficiency. Biochemical studies revealed an increased CK level (table 1). Elsewhere, an EMG had been recorded and a muscle biopsy performed in view of probable myopathy. The EMG showed non-specific myopathic changes and the muscle biopsy specimen (not biochemically examined) showed only non-specific changes. Symptoms had gradually progressed in subsequent years. The patient developed fatigability, dyspnoea and dysphagia. Intermittent carbon dioxide retention and disturbed powers of concentration was observed in 1980.

In January 1981 we saw an extremely thin, dyspnoeic man (height $2 \mathrm{~m}$, body weight $43 \mathrm{~kg}$ ) who showed hardly any excursion on inspiration and expiration. Neurological examination revealed a myopathic facies and dysarthria. Muscular atrophy of the extremities was proximally more pronounced than distally. Reflexes were weak on both sides. Biochemical studies showed respiratory acidosis and an increased CK level (424 U/l). The vital capacity was $1550 \mathrm{ml}$ (normal value $6250 \mathrm{ml}$ ). The patient required no artificial ventilation and was discharged in a very moderate pulmonary condition. Since acid maltase deficiency had been diagnosed in his brother (patient 8 ), this diagnosis seemed highly likely. Four months later he was readmitted with acute respiratory failure leading to respiratory and cardiac standstill and death. Necropsy confirmed the diagnosis of acid maltase deficiency.

\section{Discussion}

Acid maltase deficiency (Pompe's disease) is an autosomal recessive hereditary metabolic disorder characterised by glycogen storage and associated with deficiency of the lysosomal enzyme acid maltase ( $\alpha$-1, 4-glucosidase). Clinically, a generalised infantile early lethal form is distinguished from a slowly progressive adult onset form which is limited to the skeletal muscles. The adult onset form typically shows proximal muscular insufficiency with a normal or diminished reflex pattern.

The adult onset form is characterised by selective muscle involvement; not all muscles are equally affected. Macroscopic examination shows severely affected muscle bundles alongside hardly affected bundles (fig). More severe involvement of the diaphragm than of the skeletal musculature leads to respiratory failure with intact locomotor function. Respiratory failure developed early in the course of the disease in five of our nine patients and was the initial symptom in four (table 1). This corroborates the findings reported by Rosenow. ${ }^{2}$ Respiratory failure is preceded by a period of disturbed concentration, morning headaches and intermittent carbon dioxide retention. The cause of the respiratory failure in acid maltase deficiency is not entirely clear. In addition to respiratory muscle fatigue, intercurrent infections and the consequences of the high $\mathrm{CO}_{2}$ concentration (cardiac decompensation, pulmonary hypertension) are considered to be implicated. Roussos $^{5}$ demonstrated that muscle fatigue of the diaphragm can generally occur in association with respiratory failure. This muscle fatigue probably explains why it takes at least 1-2 weeks before the patients can be entirely weaned from artificial ventilation (table 2); this time is required for restoration of diaphragmatic function.

Contributing causes of respiratory failure mentioned in the literature are paralysis of the diaphragm, ${ }^{6}$ diminished excitability of the chemoreceptors $^{3}$ and motor neuron disease. ${ }^{7}$

Respiratory failure as an early symptom of neuromuscular disease is rare but it has been described, not only in acid maltase deficiency but also in motor neuron disease,${ }^{89}$ myasthenia gravis, ${ }^{10}$ Werdnig-Hoffmann disease. ${ }^{11}$

Diagnostic problems are the low incidence, failure to identify long-standing poor muscular performance and the secondary manifestations caused by hypoventilation. Moreover, artificial ventilation always poses diagnostic problems: intubation impedes proper history-taking and confinement to bed makes it difficult to assess motor function and gait. Supplementary findings such as CK level and EMG are not always indicative of a myopathy (table 1).

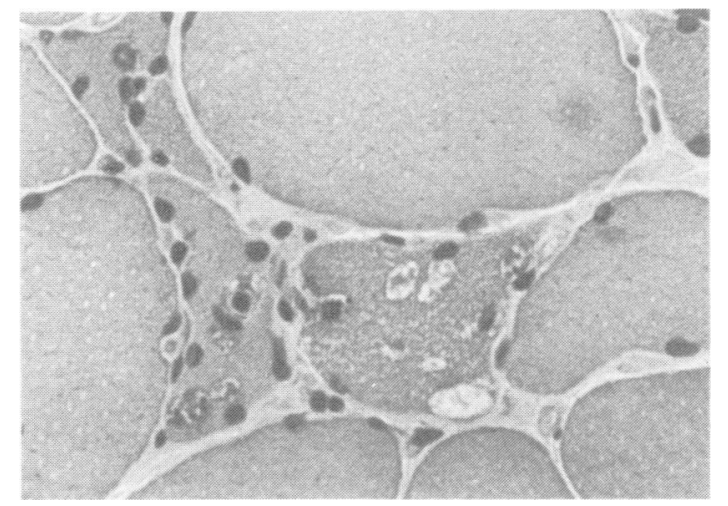

Fig M. quadriceps femoris. There is an increased variability of fibre diameters. Some fibres show peripherally and centrally located vacuoles with granular contents. (haematoxylin, eosin $\times 500$ ) 
The CK level was increased in nearly all our patients, but this was independent of the severity of the disease. Owing to the selective muscle involvement a normal EMG can be recorded in patients with manifest acid maltase deficiency. Electromyography of the paravertebral musculature is important. In no case did the EMG give indications of a neurogenic disease. Most EMG records showed myopathic changes with pseudomyotonic volleys (table 1). The diagnosis was established on the basis of the acid maltase concentration in leucocytes, muscles and sometimes urine. This concentration was found to be decreased in all cases except patient 2 . In one patient the myoadenylate deaminase level was decreased as well. Deficiency of this muscle enzyme has been described in several neuromuscular diseases and may be one of the causes of familial exertional myalgia. ${ }^{12}$

The muscle biopsy specimen is conclusive of acid maltase deficiency. It reveals vacuolar myopathy and histochemical staining with periodic acid Schiff reagent shows that the vacuoles are filled with glycogen (PAS-positive and PAS-negative after processing with amylase). Staining also reveals a high acidphosphatase activity in the vacuoles which proves lysosomal origin (fig).

There is no therapy for acid maltase deficiency. Enzyme substitution and stimulation of glycogenolysis have been unsuccessful. ${ }^{13}$ Efforts focus on symptomatic treatment and genetic counselling. In cases with respiratory failure the patient should be artificially ventilated, dependent on the severity of the clinical symptoms. Diaphragm training by forced expiration exercises has improved pulmonary function in these patients. ${ }^{14}$

When respiratory failure develops, the prognosis varies. Two patients died immediately after admission (patients 4 and 5). Three patients were artificially ventilated over periods ranging from one to four weeks. Recurrence of respiratory failure led to a fatal issue in two cases (patients 2 and 3 ). Patient 1 is artificially ventilated at night in order to prevent the consequences of $\mathrm{CO}_{2}$ storage, nocturnal respiratory arrest and pulmonary hypertension.'
Dr $\mathbf{R}$ Wevers performed the biochemical studies and Dr H Ter Laak performed the neuropathological examinations.

\section{References}

' Newsom Davis JM, Goldman M, Loh L, Casson M. Diaphragm function and alveolar hypoventilation. $Q J$ Med 1975; XLV:87-100.

${ }^{2}$ Rosenow EC, Engel AG. Acid maltase deficiency in adults presenting as respiratory failure. $\mathrm{Am} \mathrm{J} \mathrm{Med}$ 1978; 64:485-91.

${ }^{3}$ Bellamy D, Newsom Davis JM, Hickey BP, Benatar SR, Clark TJH. A case of primary alveolar hypoventilation associated with mild proximal myopathy. Rev Resp Dis 1975;112:867-73.

${ }^{4}$ Lightman NI, Schooley RT. Adult onset acid maltase deficiency. Chest 1977;77:250-2.

${ }^{5}$ Roussos CS, Grassino A, Macklem PT. Inspiratory muscle fatigue and acute respiratory failure. Can Med Assoc. 1980;122:1375-7.

- Sivak ED, Salanga VD, Wilbourn AJ, Mitsumoto H, Golish J. Adult onset acid maltase deficiency presenting as diaphragmatic paralysis. Ann Neurol 1981;9:613-5.

7 Karpati G, Carpenter S, Eisen A, Aubé M, DiMauro S. The adult form of acid maltase deficiency. Ann Neurol 1977;9:276-80.

${ }^{8}$ Hill R, Martin J, Hakim A. Acute respiratory failure in motor neuron disease. Arch Neurol 1983;40:30-2.

${ }^{9}$ Parhad I, Clark A, Barron K, Staunton SB. Diaphragmatic paralysis in motor neuron disease. Neurology (Minneap) 1978;28:18-22.

${ }^{10}$ Simpson JA. Myasthenia gravis: a new hypothesis. Scott Med J 1960;5:419-36.

"Mellins RB, Hays AP, Gold AP, Berdon WE, Bowdler JD. Respiratory distress as the initial manifestation of Werdnig-Hoffmann disease. Pediatrics, 1974; 53:33-40.

12 Kelemen J, Rice DR, Bradley WG, Munsat TL, DiMauro S, Hogan EL. Familial myoadenylate deaminase deficiency and exertional myalgia. Neurology (NY) 1982; 32:857-63.

${ }^{13}$ Loonen M. The variability of Pompe's disease. Thesis 1979. Rotterdam.

14 Martin RJ, SuFit RL, Ringel SP, Hudgel DW, Hill PL. Respiratory improvement by musle training in adult onset acid maltase deficiency. Muscle Nerve 1983; 6:201-3. 